\title{
ANÁLISE DA RESISTÊNCIA MECÂNICA DO CONCRETO VARIANDO DIFERENTES PROCESSOS DE CURA
}

\author{
SANTOS, JONHNATAN SANTANA \\ Graduando em Engenharia Civil \\ Centro Universitário FG - UniFG \\ Bahia; Brasil \\ jhwsantos.egc@gmail.com
}

CAETANO, MATEUS RIBEIRO

Graduando em Engenharia Civil

Centro Universitário FG - UniFG

Bahia; Brasil

caetano.mr@outlook.com

\author{
RODRIGUES, LUDMYLLA PEREIRA \\ Graduanda em Engenharia Civil \\ Centro Universitário FG - UniFG \\ Bahia; Brasil \\ ludy.gbi@hotmail.com
}

\author{
TEIXEIRA, OTACISIO GOMES \\ Docente, mestre em Engenharia Civil \\ Centro Universitário FG - UniFG \\ Bahia; Brasil \\ otacisiogteixeira@hotmail.com
}

\author{
Docente, mestre em Geotecnia \\ Centro Universitário FG - UniFG \\ Bahia; Brasil \\ humbertolar@gmail.com
}

FILHO, HUMBERTO LARANJEIRA DE SOUZA

\section{RESUMO}

O procedimento de cura do concreto é uma etapa essencial para evitar a perda da água de hidratação do cimento. Como consequência, a correta aplicação deste método irá proporcionar melhores resultados quanto à qualidade e resistência mecânica deste material. Em vista disso, o presente estudo tem como objetivo avaliar a resistência mecânica dos corpos de prova para diferentes processos de cura. Para isso, foram realizados ensaios de compressão axial e tração por compressão diametral com prensa hidráulica manual, visando identificar a resitência do concreto estudado. Os agregados foram caracterizados através dos ensaios de granulometria, massa específica e massa unitária. Além disso, também foi determinado o teor de umidade e módulo de finura. Para a execução dos ensaios foram elaborados dois traços, sendo traço A e B, cada um com 24 corpos de prova. A partir dos resultados obtidos, foi possível observar a efetividade da cura úmida em ganho de resistência. A cura por aspersão também apresentou resultados que devem ser levados em consideração, ainda que no traço B a resistência foi inferior ao mínimo estabelecido. Os CPs que foram submetidos a cura seca e em estufa à $50^{\circ} \mathrm{C}$ não apresentaram resultados satisfatórios. Os resultados tomaram como base a resistência mínima de 20 MPa estabelecida pela norma para concreto estrutural.

Palavras-chave: Cura do Concreto, Qualidade, Resistência, Compressão, Tração.

\section{ABSTRACT}

The concrete curing procedure is an essential step in order to avoid the loss of cement hydration water. Consequently, the correct application of this method will provide better results regarding the quality and mechanical resistance of this material. In view of this, the present study aims to evaluate the mechanical resistance of the specimens for different healing processes. For that, tests of axial compression and traction by diametrical compression were carried out with a manual hydraulic press, aiming to identify the strength of the studied concrete. The aggregates were characterized through the tests of granulometry, specific mass and unit mass. In addition, the moisture content and fineness modulus were also determined. For the execution of the tests, two lines were created, line A and B, each with 24 specimens. From the results obtained, it was possible to observe the effectiveness of wet curing in resistance gain. The spray cure also showed results that must be considered, although in line B, the resistance was lower than the established minimum. The CPs that were submitted to dry and oven curing at $50{ }^{\circ} \mathrm{C}$ did not present satisfactory results. The results were based on the minimum strength of $20 \mathrm{MPa}$ established by the standard for structural concrete. Keywords: Concrete Curing, Quality, Strength, Compression, Tensile. 


\section{INTRODUÇÃO}

A cura do concreto é um procedimento de extrema importância para se obter qualidade e durabilidade em materiais cimentícios. De forma geral, consiste em evitar a evaporação prematura da água do amassamento, para garantir que os os compostos do cimento se hidratem corretamente (BATTAGIN et al., 2002). O concreto e todos elementos produzidos por ele, devem ser executados em conformidade com as normas vigentes, pois é mediante a correta execução do seu processo de produção que se obterão as melhores propriedades do concreto. Entretanto, é notório que este procedimento tem sido amplamente negligenciado em campo (SARAIVA, 2018).

O concreto deve ser mantido em cura no intuito de evitar a perda de água pela superfície, assegurando que esta seja durável e alcance a resistência esperada. A água como agente no processo de cura é crucial para evitar a auto dessecação, ou seja, processo onde a água é perdida internamente, sendo necessário hidratar o concreto constantemente por um período mínimo. Deste modo, o procedimento evitará a perda de água pela superfície, o qual irá contribuir em ganho de resistência (NEVILLE; BROOKS, 2013).

A evaporação da água pela superfície do concreto deve ser controlada de forma eficiente visando a melhor resistência a esforços dos elementos, podendo se tornar um perigo à sua resistência, pois se perde parte da água necessária à hidratação, podendo surgir microfissuras, consequentemente não atingindo a qualidade desejada (OESTREICH et al., 2013).

Por intermédio dos ensaios de compressão axial, recomendados pela ABNT NBR 5739:2018 e pela ABNT NBR 7222:2010 é possível a verificação da influência da cura na resistência quando alternado os procedimentos para concreto de mesmo parametro de resistência . No presente estudo foram analisadas distintas situações de cura em corpos de prova (CPs) de concreto. A cura úmida, procedimento recomendado pela ABNT NBR 5738:2016. Além disso, a verificação da influência da temperatura na resistência mecânica dos corpos de prova em estufa.

Com isto, o presente trabalho objetiva analisar a resistência mecânica de corpos de prova de concreto submetidos a diferentes metodologias de cura. Pois, ainda é muito presente em obras a produção do concreto sem o processo de cura, ou mesmo de forma inadequada, coincidentes com as análises feitas. Deste modo, será possível relacionar o desempenho de cada método para, por fim, destacar a influência deste procedimento no ganho da resistência deste material.

\section{MATERIAL E MÉTODOS}

A realização da pesquisa se deu com a utilização dos seguintes materiais: Cimento Portland CP II F 32, agregado miúdo, agregado graúdo (brita tipo 0) e água para a mistura do concreto. A execução dos ensaios foi realizada no Laboratório de Materiais de Construção do Centro Universitário FG - UniFG, Guanambi - BA.

\subsection{Caracterização dos Materiais}

É importante ressaltar que, todos os corpos de prova moldados neste estudo utilizaram materiais de mesma procedência, no intuito de mitigar possíveis variações nos resultados. A caracterização dos agregados, no âmbito desta pesquisa, teve como principal finalidade utilizar tais resultados na dosagem para obtenção do traço e, por se tratar de materiais extraídos da natureza, não recebem um rigoroso controle de qualidade como ocorre no cimento.

\subsubsection{Agregado Miúdo}

O ensaio de composição granulométrica do agregado miúdo foi executado conforme as recomendações da ABNT NBR NM 248:2003. A curva granulométrica pode ser observada pela Figura 1. A partir da análise granulométrica foi possível também determinar o módulo de finura do agregado, obtido pela soma dos percentuais acumulado das peneiras da série normal, dividida por 100. 


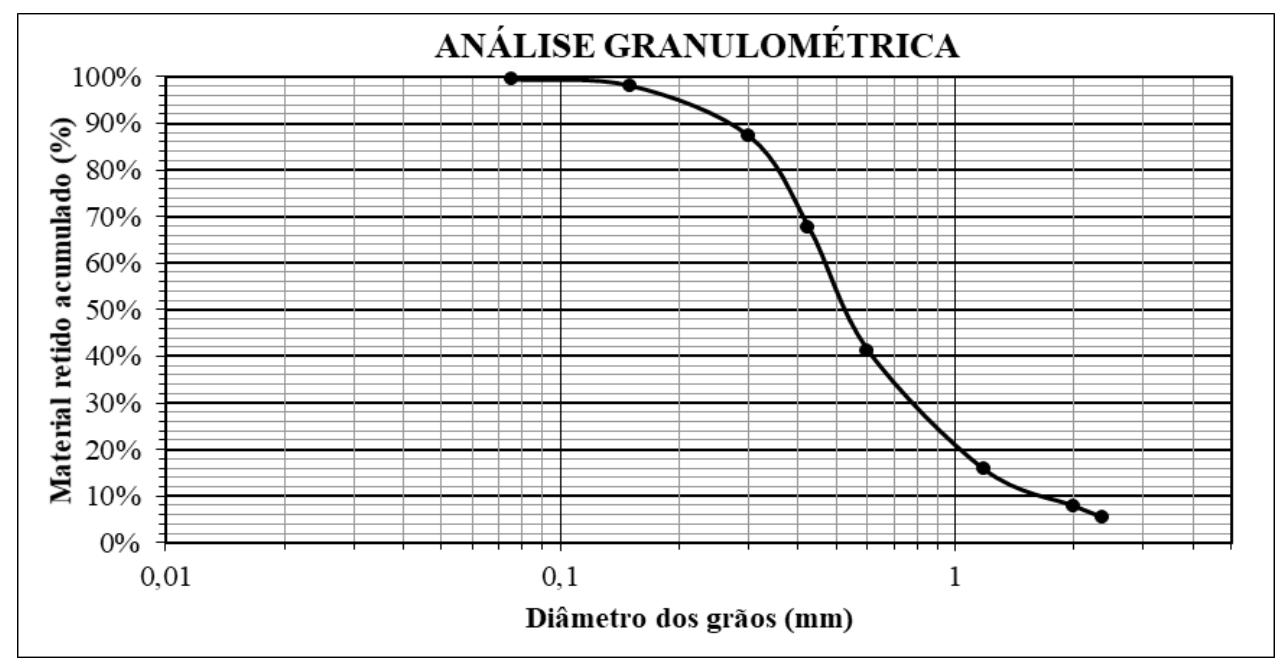

Figura 1: Curva de composição granulométrica do agregado miúdo.

Fonte: Autor, 2020.

A massa específica foi obtida de acordo o que preconiza a ABNT NBR NM 52:2009. A massa unitária do agregado foi determinada conforme a ABNT NBR NM 45:2006. Os valores obtidos nos ensaios de caracterização para o agregado graúdo podem ser observados na Tabela 1 .

Tabela 1 - Características do agregado miúdo.

\begin{tabular}{c|c|c|c}
\hline Teor de Umidade & Módulo de Finura & Massa Específica & Massa Unitária \\
\hline $1 \%$ & 3,5 & $2,65 \mathrm{~g} / \mathrm{cm}^{3}$ & $1,60 \mathrm{~g} / \mathrm{cm}^{3}$ \\
\hline
\end{tabular}

Fonte: Autor, 2020.

A partir do módulo de finura (MF), classificou-se o agregado como areia média. A classificação foi definida de acordo Ambrozewicz (2012) descrito na Tabela 2.

Tabela 2 - Classificação do agregado miúdo.

\begin{tabular}{c|c|c}
\hline Areias Grossas & Areias Médias & Areias Finas \\
\hline $\mathrm{MF}>3,9$ & $3,9>\mathrm{MF}>2,4$ & $\mathrm{MF}<2,4$ \\
\hline
\end{tabular}

Fonte: Ambrozewicz, 2012.

\subsubsection{Agregado Graúdo}

Assim como para o agregado miúdo, o ensaio de composição granulométrica foi executado conforme as recomendações da NBR NM 248 para o agregado graúdo. Obteve-se o teor de umidade pela pesagem e secagem em estufa, por 24 horas. A curva granulométrica pode ser observada pela Figura 2. 


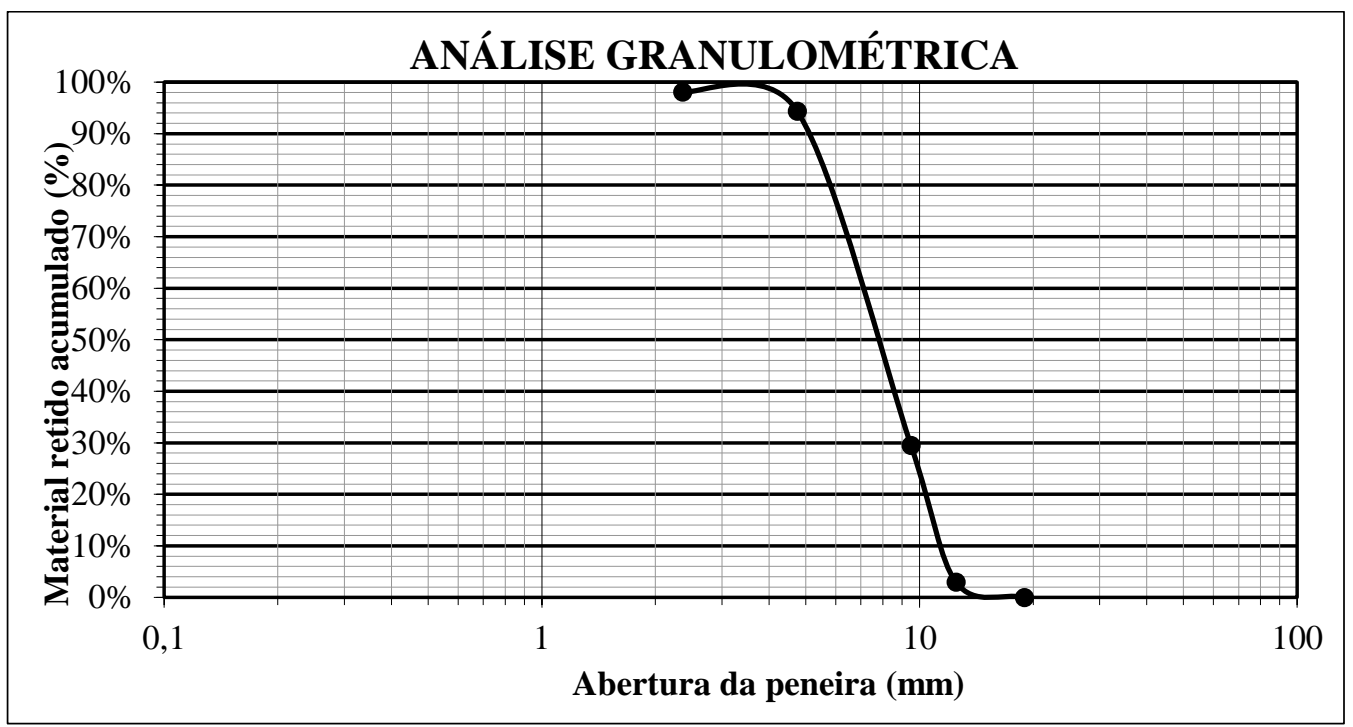

Figura 2: Curva de composição granulométrica do agregado graúdo.

Fonte: Autor, 2020.

A massa específica foi obtida de acordo o que preconiza a ABNT NBR NM 53:2009 - Agregado graúdo - Determinação de massa específica, massa específica aparente e absorção de água. O procedimento foi realizado três vezes para ambos os agregados e a massa específica determinada pela média entre eles.

A massa unitária foi determinada conforme a NM 45:2006, assim como para o agregado miúdo. Por fim, no Tabela 3 podem ser observados os valores obtidos a partir da caracterização do agregado graúdo.

Tabela 3 - Características do agregado graúdo.

\begin{tabular}{c|c|c}
\hline Teor de Umidade & Massa Específica & Massa Unitária \\
\hline $0 \%$ & $2,69 \mathrm{~g} / \mathrm{cm}^{3}$ & $1,39 \mathrm{~g} / \mathrm{cm}^{3}$ \\
\hline
\end{tabular}

Fonte: Autor, 2020.

\subsection{Traço e Moldagem dos Corpos de Prova}

O Traço A foi definido baseado no conhecimento comum adotado em obras no município de Guanambi-BA, sendo a proporção de 1:2:3:0,5. O Traço B foi calculado conforme o método da Associação Brasileira de Cimento Portland (ABCP/ACI, 1994) citado por Boggio (2000), na proporção de 1:2,3:2,1:0,59, para um concreto com $20 \mathrm{MPa}$. As proporções foram fixadas em massa como descrito na Tabela 4.

Tabela 4 - Traço em massa.

\begin{tabular}{c|c|c|c|c}
\hline Traço & Cimento $(\mathrm{kg})$ & Agregado Miúdo $(\mathrm{kg})$ & $\begin{array}{c}\text { Agregado Graúdo } \\
(\mathrm{kg})\end{array}$ & Água $(\mathrm{kg})$ \\
\hline Traço A & 15 & 30 & 45 & 7,5 \\
\hline Traço B & 16 & 36,8 & 33,6 & 9,44 \\
\hline
\end{tabular}

Fonte: Autor, 2020.

A mistura do concreto procedeu-se em betoneira elétrica com capacidade de 120 litros, seguindo as orientações de Bauer (2009). De acordo com o autor, não existe uma regra geral para a ordem de colocação dos materiais, porém deve se atentar para alguns cuidados na utilização de betoneiras pequenas. Recomenda-se adicionar primeiro a água e o agregado graúdo, em seguida a adição do cimento e por fim o agregado miúdo. 
Preparado o concreto, prosseguiu-se com a execução do slump test para verificação do concreto em seu estado fresco, conforme as recomendações da ABNT NBR NM 67:1998 para abatimento do concreto do tronco de cone. O abatimento foi medido conforme a Figura 3. O abatimento foi de $3 \mathrm{~cm}$ e $18 \mathrm{~cm}$ para os Traços A e B, respectivamente.

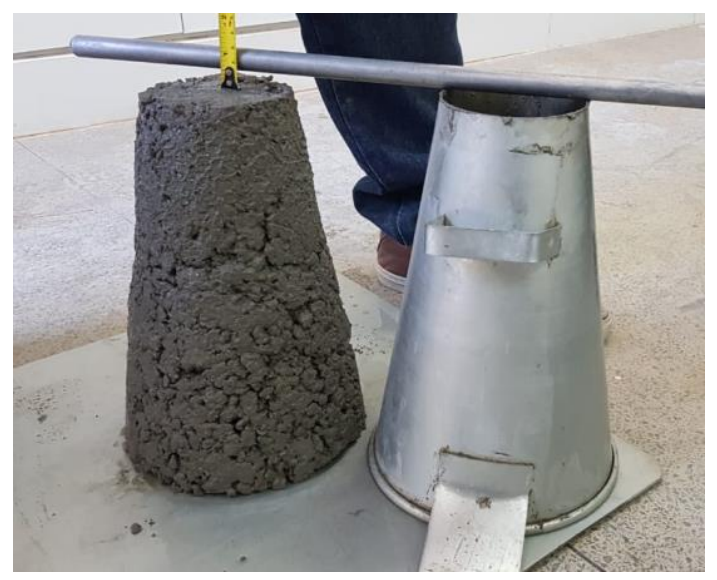

Figura 3: Execução do slump test.

Fonte: Autor, 2020.

Os instrumentos utilizados, bem como a moldagem dos corpos de prova seguiram a norma técnica ABNT NBR 5738:2015. Foram utilizados cilindros de $20 \mathrm{~cm}$ de altura por $10 \mathrm{~cm}$ de diâmetro. Foram moldados 24 corpos de prova para cada traço, sendo seis CPs para cada metodologia de cura, três para cada ensaio (Compressão e Tração), totalizando a moldagem de 48 (quarenta e oito) CPs.

\subsection{Procedimento de Cura}

Após 24h da execução da moldagem, os corpos de prova foram desmoldados e devidamente identificados. Em seguida os mesmos foram submetidos a situações variadas de cura adotadas nesse estudo, durante um período de 14 dias, tendo em vista que por definição a norma estabelece periodo minimo de 7 dia, tendo sido adotado o dobro do tempo mínimo. Após esse período todos foram armazenados e protegidos em um ambiente livre de intempéries até o momento do teste de resistência. O rompimento dos corpos de prova foi realizado para a idade de 28 dias.

\subsubsection{Cura Úmida}

A cura úmida foi executada conforme o que preconiza a ABNT NBR 5739:2018, onde, manteve-se a superfície do corpo de prova completamente úmida e submersa até o fim do processo de cura. A Figura 4 ilustra o procedimento.

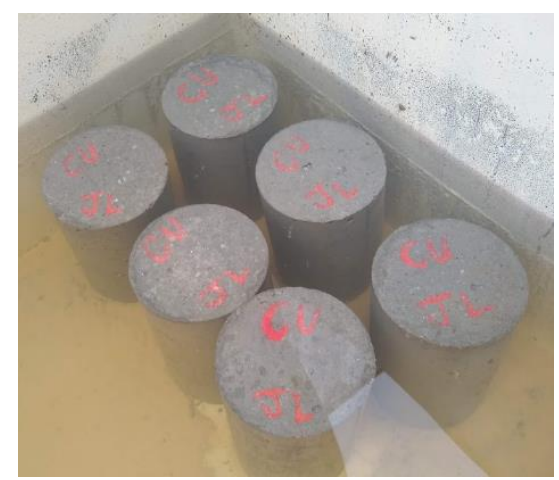

Figura 4: Procedimento de cura úmida. Fonte: Autor, 2020.

\subsubsection{Cura por Aspersão}

A cura por aspersão se deve à distribuição de gotículas de água sobre a superfície do corpo de prova de forma contínua, suficiente apenas para saturar a superfície (OESTREICH et al., 2013). Deste modo, o procedimento consistiu-se na 
saturação de toda a superfície do CP com o auxílio de um borrifador com água, em periodos regulares e com frequência de uma vez por dia, durante todo o periodo de cura. Manteve-se armazenados no ambiente interno do laboratório e livre de exposições de intemperismo.

\subsubsection{Cura Seca}

Realizou-se a cura seca ao ar livre. Assim chamada neste estudo, pois não esteve submetida a nenhum tratamento de cura. Durante o período de cura, o material esteve exposto ao intemperismo em um ambiente não controlado, sofrendo variações de temperatura e de outros agentes presentes em ambiente natural. Pela Figura 5 pode-se observar o armazenamento dos CPs no ambiente externo.

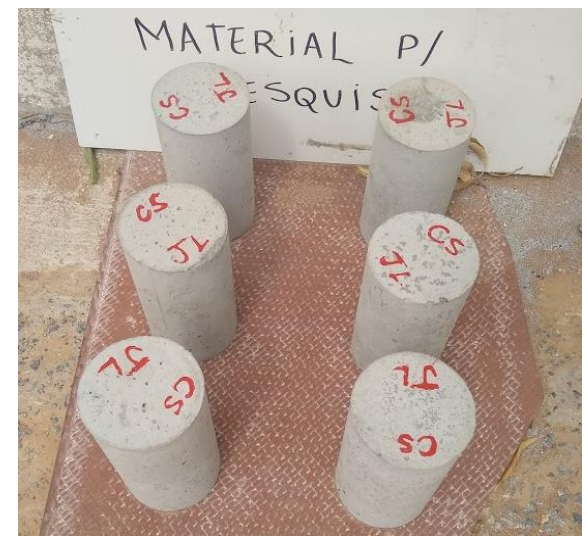

Figura 5: Procedimento de cura seca.

Fonte: Autor, 2020.

\subsection{Influência da Temperatura}

Realizou-se também, a verificação da influência da temperatura em estufa com temperatura à $50{ }^{\circ} \mathrm{C}$ constante, essa temperatura foi escolhida para evitar a desidratação acelerada dos CP. Deste modo, buscou-se verificar uma pior hipótese dos efeitos da temperatura no concreto em relação às demais. Realizou-se esta análise à parte das demais curas por não se tratar de um procedimento que se aplica em campo, ou até mesmo em laboratório. A Figura 6 ilustra o procedimento realizado em estufa.

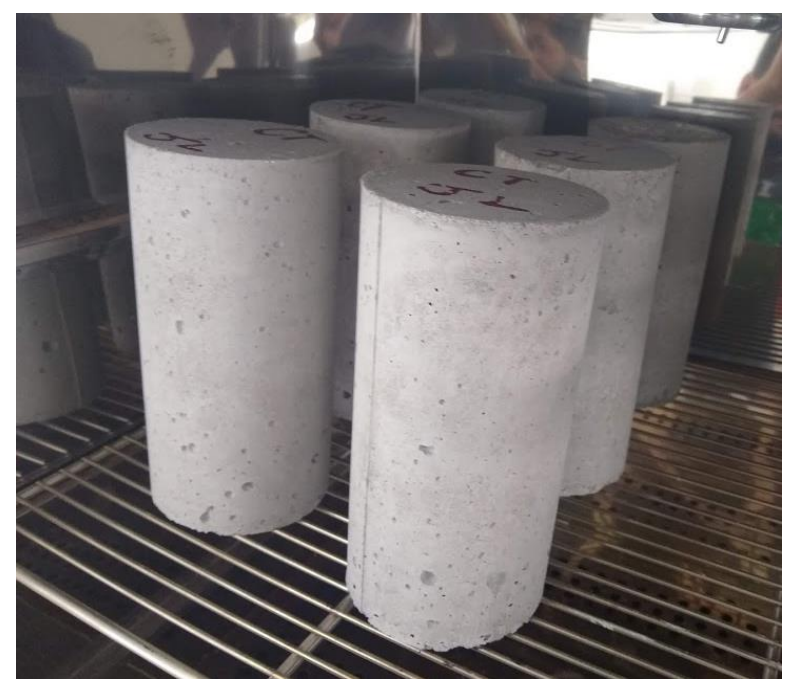

Figura 6: Procedimento de verificação da influência da temperatura em estufa.

Fonte: Autor, 2020.

\subsection{Ensaios de Compressão e Tração}

Após o período da cura, realizou-se o rompimento dos corpos de prova para verificação da resistência mecânica quanto aos esforços de compressão axial e tração por compressão diametral. Os ensaios são normatizados pela ABNT NBR 
5739:2018 onde determina-se os procedimentos para o ensaio de compressão de corpos de prova cilíndricos de concreto e pela ABNT NBR 7222:2010 para determinar da resistência à tração por compressão diametral de corpos de prova cilíndricos de argamassa e concreto.

No ensaio de compressão, o corpo de prova foi posicionado na prensa hidráulica manual de forma que o seu centro estivesse coerente com o eixo da máquina, executando em seguida o rompimento do CP. No ensaio de tração, o corpo de prova foi posicionado na horizontal entre duas placas apoiadas, no intuito de manter uniforme a distribuição da força por toda a extensão do $\mathrm{CP}$, executando assim o rompimento do mesmo.

As Figuras 7 e 8 ilustram a execução do ensaio de compressão e tração.

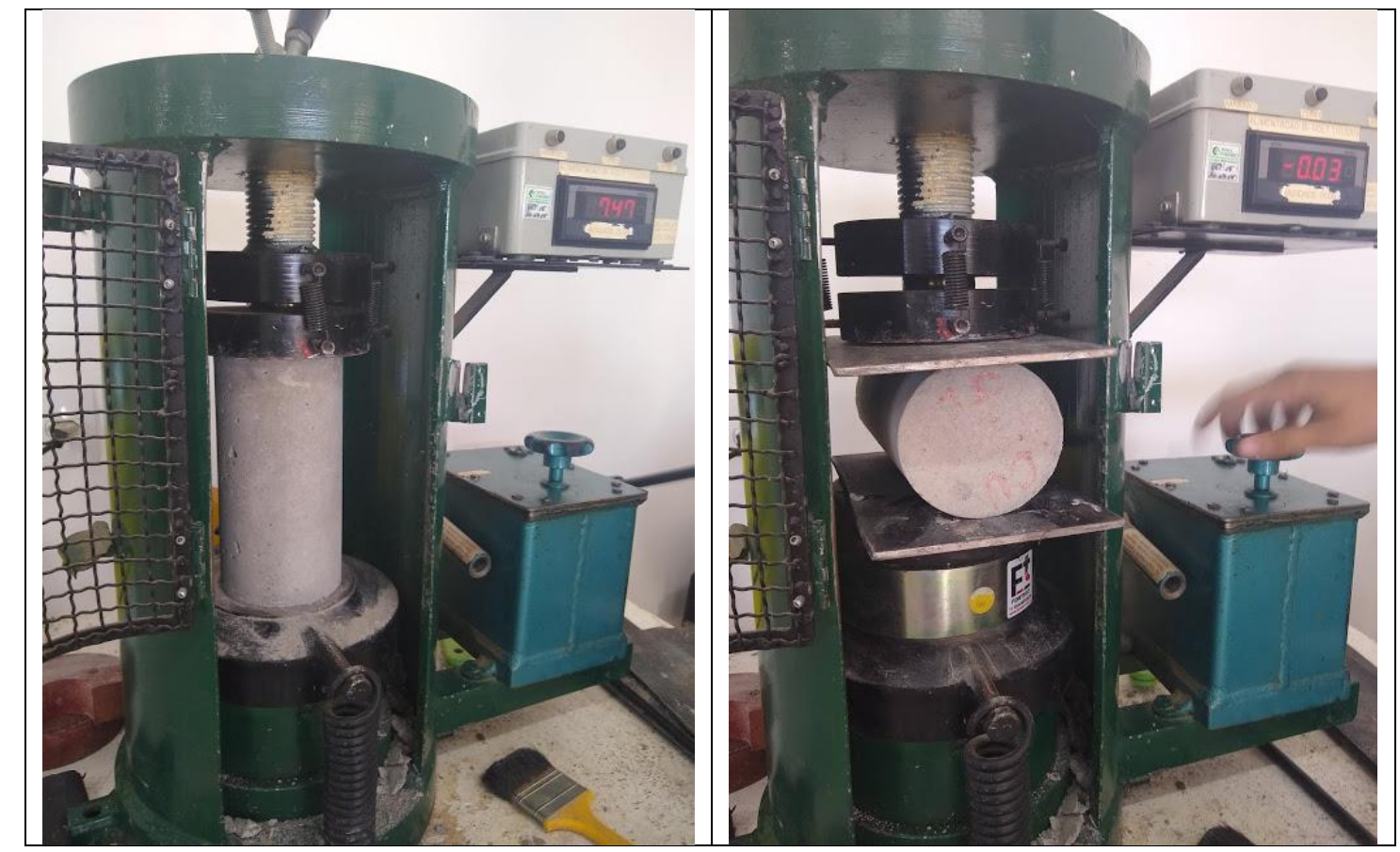

Figura 7: À esquerda, execução do ensaio de compressão axial. À direita, execução do ensaio de tração por compressão diametral.

Fonte: Autor, 2020.

\section{RESULTADOS E DISCUSSÃO}

Os resultados foram obtidos por meio da resistência média dos corpos de prova, e estão apresentados pelos gráficos de barras a seguir. Cada gráfico apresenta os resultados para o Traço A e Traço B, conforme ilustram as Figuras 8 e 9 . Devese ressaltar que os resultados obtidos devem ser considerados para os materiais empregados nesta pesquisa. Os resultados podem apresentar variações em materiais diferentes, em especial o tipo de cimento adotado. 

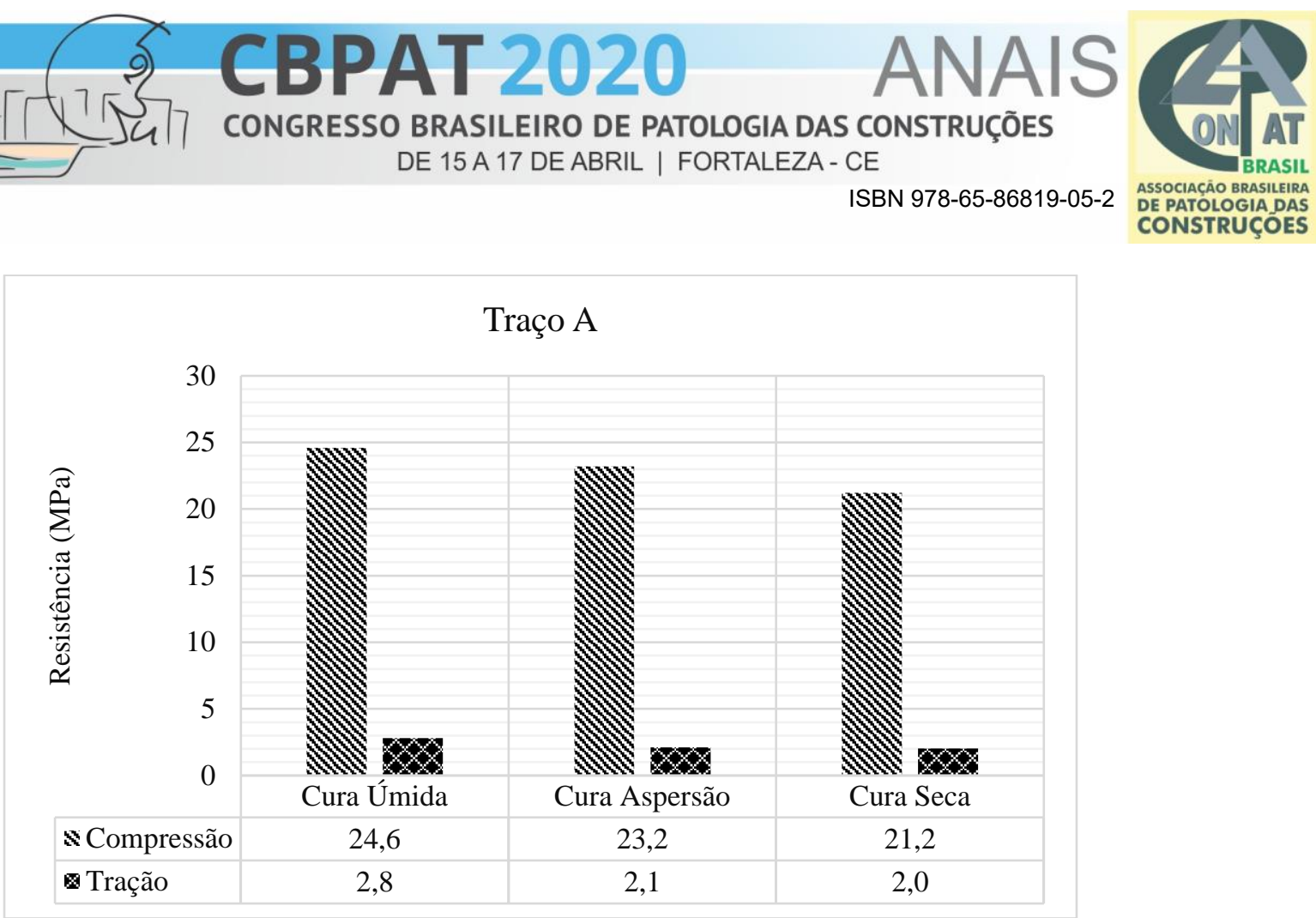

Figura 8: Resistência à compressão e tração do Traço A.

Fonte: Autor, 2020.

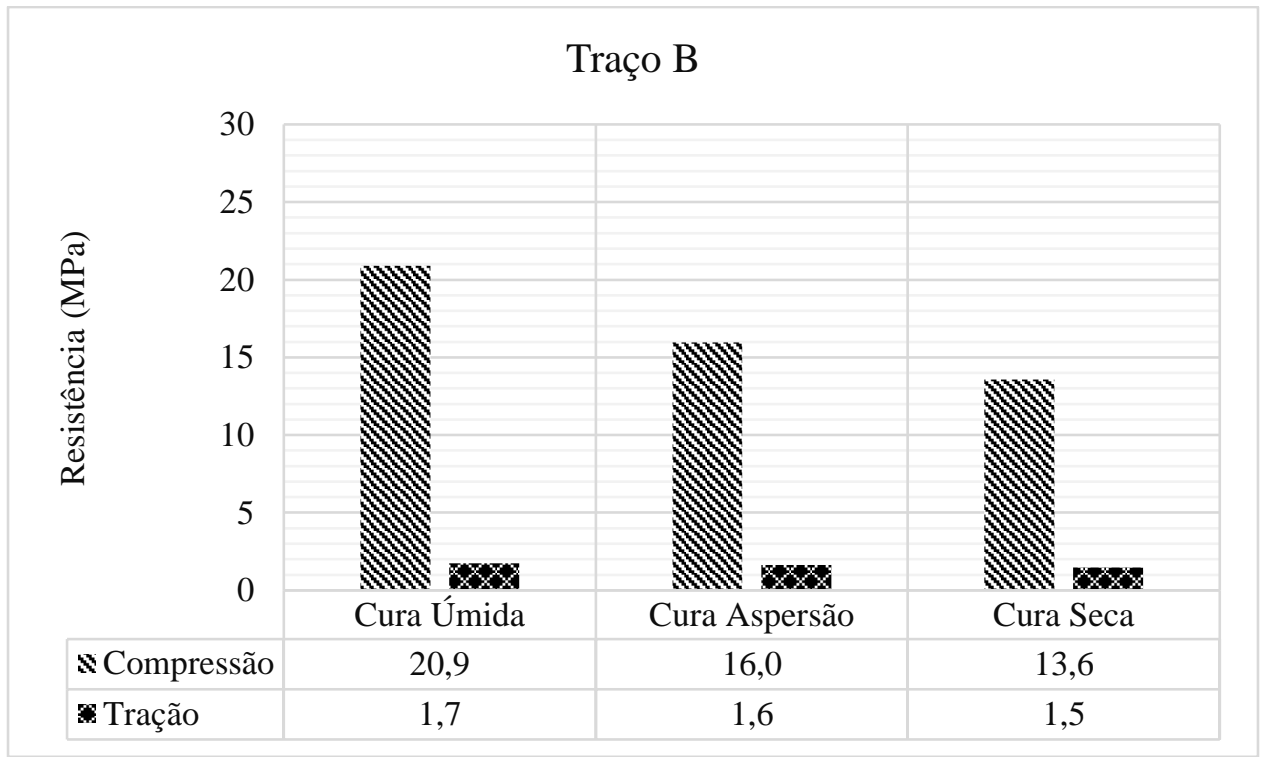

Figura 9: Resistência à compressão e tração do Traço B.

Fonte: Autor, 2020.

A partir do gráfico apresentado pela Figura 9, observa-se uma perda nos valores da resistência mecânica dos corpos de prova, tanto para a compressão quanto para a tração. Com base no melhor desempenho, obtido pela cura úmida, tem-se então a porcentagem da variação da perda da resistência dos demais procedimentos de cura, conforme a Tabela 5 .

Tabela 5 - Perda da resistência para o Traço A em relação à cura úmida.

\begin{tabular}{c|c|c}
\hline Tipo de Cura & Compressão & Tração \\
\hline Aspersão & $-5,7 \%$ & $-25 \%$ \\
\hline Seca & $-13,8 \%$ & $-28,6 \%$ \\
\hline
\end{tabular}

Fonte: Autor, 2020. 
Os dados demonstram uma perda na resistência, tanto à compressão quanto à tração. A cura seca foi o procedimento que teve maior perda na resistência. Enquanto que a cura por aspersão obteve uma queda relativamente baixa em relação à cura úmida. A partir dessa análise, percebe-se a importância da contribuição do mínimo de água no procedimento de cura para alcançar a resistência desejada.

Assim como para o Traço A, para o Traço B também obteve-se a relação da perda da resistência em comparação com a cura úmida. Os valores são apresentados na Tabela 6 com base nos valores obtidos e descritos na Figura 9.

\begin{tabular}{c|c|c}
\multicolumn{2}{c}{ Tabela 6 - Perda da resistência para o Traço B em relação à cura úmida. } \\
\hline Tipo de Cura & Compressão & Tração \\
\hline Aspersão & $-23,4 \%$ & $-6 \%$ \\
\hline Seca & $-35 \%$ & $-12 \%$ \\
\hline
\end{tabular}

Fonte: Autor, 2020.

Os resultados apresentados para o Traço B apresentam uma variação negativa em relação ao Traço A, visto que, somente a cura úmida alcançou o valor de resistência esperado. Observa-se que a perda de resistência no Traço B foi maior que no Traço A em todas as situações de cura.

A representação dos gráficos ilustrados anteriormente verifica que para ambos os traços, as resistências apresentam comportamento similar, indicando a eficiência da cura para cada metodologia. A discrepância da resistência mecânica entre os traços era esperada, uma vez que para cada concreto produzido a dosagem dos materiais foi diferente, o que torna inconclusivo afirmar que esta perda está exclusivamente relacionada ao método de cura.

Ainda que a dosagem do Traço B tenha sido calculada, esperava-se um melhor desempenho, em comparação com o Traço A, por se tratar de uma dosagem empírica. O controle de qualidade quanto à dosagem feita em laboratório, não deve ser equiparada com a execução da mistura feita em campo, que por sua vez dispõe de menores atenções quanto a precisão das etapas de execução de produção do concreto.

Outro fator que deve ser levado em consideração são os resultados do Slump Test, que verifica a consistência influenciada pela relação a/c (água/cimento) do concreto. No Traço A, o Slump foi de $3 \mathrm{~cm}$, enquanto no Traço B, o Slump foi de 18 $\mathrm{cm}$. O excesso de água na mistura melhora a trabalhabilidade e fluidez do concreto, porém resulta na porosidade e, consequentemente, na perda de resistência do material (BARBOZA; BASTOS, 2008; FERNANDES; SILVA, 2011).

Conforme preconiza a NBR 6118:2014, elementos estruturais devem ter uma resistência mínima à compressão de 20 $\mathrm{MPa}$, e por tanto, somente a cura úmida apresentou um desempenho satisfatório no Traço B. Sendo assim, a utilização deste traço em elementos estruturais requer uma atenção maior, visto que o procedimento de cura, na maioria das vezes, é negligenciado em campo, como afirma Saraiva (2018).

Em relação ao Traço A, todas as metodologias de cura aplicadas se encontram em conformidade com a resistência mínima estipulada para concretos com a finalidade estrutural. Entretanto, a ausência de cura (cura seca) pode ocasionar em outros fatores que afetam a qualidade, bem como a vida útil deste concreto.

\subsection{Influência da Temperatura na Resistência Mecânica}

Os resultados obtidos para os corpos de prova submetidos à estufa durante o período de cura, podem ser observados conforme o gráfico ilustrado pela Figura 10. Vale ressaltar que, este procedimento seguiu as mesmas etapas que os demais corpos de prova, e, a sua permanência em estufa foi de 14 dias, assim como os demais procedimentos de cura. 


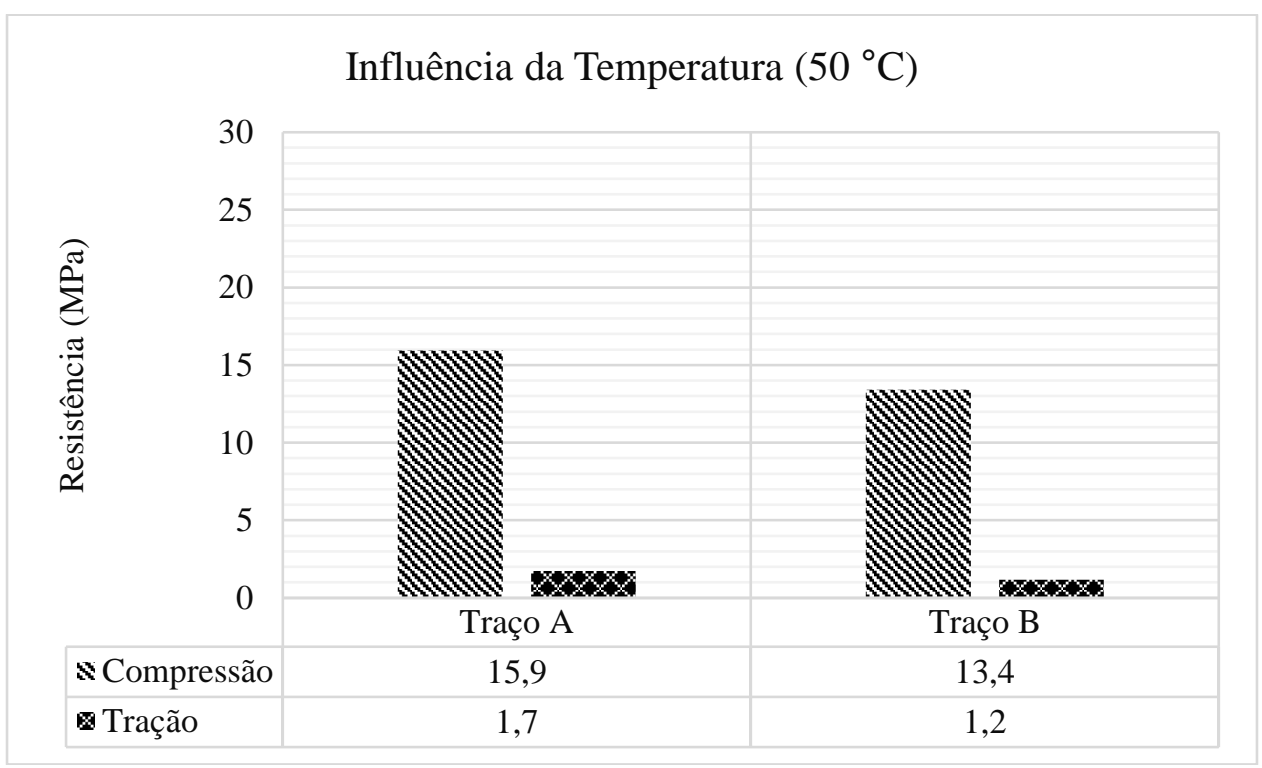

Figura 10: Resistência em corpos de prova em estufa.

Fonte: Autor, 2020.

A partir dos resultados, observa-se que nenhum dos Traços alcançou a resistência mínima à compressão de $20 \mathrm{MPa}$. Em comparação com a cura úmida, que foi o procedimento que alcançou o melhor desempenho na pesquisa, a perda de resistência para o Traço A foi de 35,4\% (compressão) e 39,4\% (tração). Para o Traço B, a perda foi de 36\% (compressão) e 29,4\% (tração). Com isto, verifica-se uma menor discrepância entre estes dois métodos, o que explica-se pelo fato de que ambos estiveram em um ambiente controlado e sujeitas à menores variáveis. Diferentemente da cura seca, que estava sujeita a um ambiente com variações do clima, e, da cura por aspersão, sujeita a variações na dosagem da água aspergida.

Em comparação geral com as demais curas, a verificação da influência da temperatura à $50{ }^{\circ} \mathrm{C}$ nos corpos de prova submetidos à estufa, demonstra que a temperatura é um fator prejudicial no período de cura do concreto. A evaporação da água na idade de 14 dias ocasionou perdas significativas na resistência do concreto, em comparação com os demais métodos de cura.

Foi feita também uma relação entre a resistência à compressão e à tração. A relação exposta na Tabela 7 demonstra quantas vezes maior são os esforços de compressão em relação à tração. De modo geral os resultados correspondem aos valores mencionados por Garcia, de 8 a 10 vezes maior (Garcia et al., 2014).

Tabela 7 - Relação da resistência à compressão em relação à tração.

\begin{tabular}{c|c|c}
\hline Tipo de Cura & Traço A & Traço B \\
\hline Umida & $8 x$ maior & $12 x$ maior \\
\hline Asperção & $11 \times$ maior & $10 x$ maior \\
\hline Seca & $10 x$ maior & $9 x$ maior \\
\hline Estufa & $9 x$ maior & $11 \times$ maior \\
\hline
\end{tabular}

Fonte: Autor, 2020.

\section{CONSIDERAÇÕES FINAIS}

De acordo com os resultados obtidos, fica evidenciada a importância da aplicação do método de cura úmida no concreto. Tal procedimento apresentou resultados satisfatórios para a resistência mecânica à compressão nos corpos de prova, alcançando valores acima de $20 \mathrm{MPa}$ para ambos os traços. O desempenho superior dos esforços de compressão em relação aos de tração condiz com os valores mencionados por Garcia (et al., 2014). 
A cura por aspersão também apresentou resultados que devem ser levados em consideração. Apesar de apresentar um desempenho inferior a $20 \mathrm{MPa}$ no Traço B, no Traço A esse valor foi superado significativamente. Isto pode ser explicado pela diferença na dosagem dos traços, que também é fator de influência na resistência mecânica dos corpos de prova de concreto.

A cura seca (ausência de cura), assim como o procedimento em estufa a $50^{\circ} \mathrm{C}$, demonstram a influência da temperatura na perda da resistência. A temperatura faz com que o corpo de prova perca a água de hidratação do cimento rapidamente e não alcance a resistência esperada. Levando em consideração o desempenho alcançado onde se aplica a cura, os valores para cura seca e em estufa apresentaram valores que podem ser indesejados num projeto.

Sugere-se, para futuras pesquisas, uma análise mais aprofundada em relação à idade dos corpos de prova, uma vez que neste trabalho foi verificada a cura somente aos 14 dias, com rompimento aos 28 dias. Outro fator que deve ser ponderado é a retificação da superfície dos CPs, uma vez que no laboratório não havia disponibilidade de equipamentos apropriados. A ausência de tais equipamentos pode ter influenciado na perda da resistência, entretanto, este fator não retira a credibilidade da verificação da influência da cura.

Por fim, com os resultados obtidos, pode-se afirmar que a cura úmida foi a que apresentou melhor desempenho em ganho de resistência, sendo um método indispensável para garantir a qualidade em estruturas de concreto onde são solicitados carregamentos que dependem da resistência do mesmo. A cura por aspersão também mostrou-se eficiente e apropriada para garantir uma resistência satisfatória no concreto.

\section{AGRADECIMENTOS}

Ao Centro Universitário FG - UniFG, pelo incentivo a pesquisa. Ao Grupo de Pesquisa em Geotecnia e Saneamento Ambiental (GESA/CNPq) e ao Observatório UniFG do Semiárido Nordestino.

\section{REFERÊNCIAS}

AMBROZEWICZ, P. H. L. Materiais de construção: normas, especificações, aplicação e ensaio de laboratório. São Paulo: Pini, 2012.

ASSOCIAÇÃO BRASILEIRA DE NORMAS TÉCNICAS. NBR 5738. Concreto - Procedimento para moldagem e cura de corpos de prova. Rio de Janeiro, 2016.

NBR 5739. Concreto - Ensaio de compressão de corpos de

prova cilíndricos. Rio de Janeiro, 2018.

NBR 6118. Projeto de Estruturas de Concreto -

Procedimento. Rio de Janeiro, 2014.

NBR 7222. Concreto e argamassa - determinação da resistência à tração por compressão diametral de corpos de prova cilíndricos. Rio de Janeiro, 2010.

. NBR NM 248. Agregados - Determinação da composição granulométrica. Rio de Janeiro, 2003.

NBR NM 45. Agregados - Determinação da massa

unitária e do volume de vazios. Rio de Janeiro, 2006.

. NBR NM 52. Agregado miúdo - Determinação da massa

específica e massa específica aparente. Rio de Janeiro, 2009.

. NBR NM 53. Agregado graúdo - Determinação de massa específica, massa específica aparente e absorção de água. Rio de Janeiro, 2009.

pelo abatimento do tronco de cone. Rio de Janeiro, 1998.

. NBR NM 67. Concreto - Determinação da consistência 
BARBOZA, M. R.; BASTOS, P. S. Traços de concreto para obras de pequeno porte. Concreto e Construção, v. 36, p. 32-36, 2008.

BATTAGIN, A. F. et al. Influência das condições de cura em algumas propriedades dos concretos convencionais e de alto desempenho. In: Congresso Brasileiro do Concreto. 2002.

BAUER, L. A. F. Materiais de construção: Novos Materiais para Construção Civil. v.1. 5. ed. Rio de Janeiro: LTC, 2009, p. 409.

BOGGiO, A. J. Estudo Comparativo de Métodos de Dosagem de Concretos de Cimento Portland. Dissertação Universidade Federal do Rio Grande do Sul, UFRGS, 2000. Disponível em:

<https://lume.ufrgs.br/bitstream/handle/10183/12575/000628682.pdf?sequence=1\&isAllowed=y >. Acesso em: 8 set. 2019.

FERNANDES, F. M.; SILVA, B. V. Influência da adição de aditivo plastificante e água para manter o abatimento ao longo do tempo na resistência à compressão do concreto. UNESC - Universidade do Extremo Sul Catarinense. Santa Catarina 2011. Disponível em: <http://repositorio.unesc.net/handle/1/1530> Acesso em: 8 out. 2019.

GARCIA, A.; SPIM, J. A.; SANTOS, C. A. Ensaios dos Materiais. 2 ed. [Reimpressão]. Rio de Janeiro: LTC 2014.

NEVILLE, A. M.; BROOKS, J. J. Tecnologia do concreto. 2. ed. Porto Alegre: Bookman, 2013. 448 p.

OESTREICH, A. M. E. Cura Térmica Utilizando Aquecimento Solar e Aspersão de Água. In: 4th International Workshop Advances in Cleaner Production. São Paulo - SP, 2013. Disponível em:

<http://www.advancesincleanerproduction.net/fourth/files/sessoes/4B/2/oestreich_et_al_report.pdf>

SARAIVA, M. A. C. Análise da Influência da Cura da Resistência à Compressão Do Concreto. Unievangélica. Anápolis - GO, 2018. Disponível em:

<http://repositorio.aee.edu.br/bitstream/aee/107/1/2018_1_TCC_Marco\%20Saraiva.pdf>. Acesso em 8 set. 2019. 